\title{
Changes in Osmotic Fragility of Erythrocytes during Exercise in Athletic Horses
}

\author{
Kei HANZAWA* and Seiki WATANABE
}

Laboratory of Animal Physiology, Tokyo University of Agriculture, 1737 Funako, Atsugi, Kanagawa

243-0034, Japan

Knowledge about changes in the osmotic fragility of erythrocytes during exercise in athletic horses which is introduced in this review can be summarized as follows; 1) Changes in the osmotic fragility of equine erythrocytes during exercise are an important indicator of intravascular haemolysis. 2) The sensitivity of the regulatory volume is decreased by a $\mathrm{K}-\mathrm{Cl}$ cotransporter, lactate and/or pH susceptibility, and the osmotic fragility of erythroid membrane due to exercise stress increases with the repeated accumulation of red cells in the spleen. 3) The increase in blood flow and the release of erythrocytes from the spleen into the circulation have little effect on the changes in the osmotic fragility of erythrocytes during exercise. 4) Increases in blood pH and temperature caused by aerobic exercises cause osmotic resistance in erythrocytes. 5) The decrease in $\mathrm{pH}$ and increase in blood lactate and peroxide caused by anaerobic exercises promotes the osmotic fragility of erythrocytes. 6) The osmotic fragility of erythrocytes could be detected by the modification, degeneration, decomposition and oxidation-reduction in cell membrane lipids and proteins, and cell volume regulation, changes which follow $p H$ and temperature changes during exercise. 7) The K-Cl cotransporter which controls the intracellular ionic homeostasis and regulatory volume decrease has a functional interrelation with the fragility of erythrocytes. The osmotic fragility of erythrocytes in athletic horses is therefore an indicator of the effects of training and/or athletic performance and stress.

Key words: erythrocytes, exercise, fragility, horse, spleen
J. Equine Sci.

Vol. 11, No. 3

pp. 51-61, 2000

\section{Contents}

I. Introduction

II. Generality

1. Fragility increased factors

2. Fragility decreased factors

III. Athletic horses

1. Exercise intensity

2. Spleen and splenectomy

3. Blood $\mathrm{pH}$ and temperature

4. Other factors

5. Indicator of athletic performance

IV. Conclusion

This article was submitted October 27, 2000 and was accepted February 13, 2001.

*Corresponding auhor.

\section{Introduction}

The osmotic fragility of erythrocytes is generally accelerated by exercise stress $[5,7,12,14,17,34,35,38$, $59,61,63-65,74]$. The increase of the fragility of erythrocytes caused by high intensity exercise is an important indicator of haemolysis in blood vessels [7, 13]. This phenomenon is evaluated in this study to discover the cause of sports anemia in human beings [7-10,65, 78].

In athletic horses, Boucher $[4,5]$ and Boucher et al. [6] suggested that the osmotic fragility of red cells and the number of echinocytes in peripheral blood were increased with exercise due to the release of erythrocytes from the spleen into the circulation, whereas Smith et al. [68] reported that exercise decreased the osmotic fragility of erythrocytes and did 
not change the percentage of red cells as echinocytes. Hanzawa et al. [24, 25, 28, 29] suggested that the frequent accumulation of erythrocytes in the spleen accelerated the cell membrane fragility in horses, and that anaerobic exercise increased the fragility of erythrocytes, but that aerobic exercise decreased it, regardless of whether or not erythrocytes were released from the spleen into the circulation.

This review first gives an outline of the increasing and/or decreasing factors related to the osmotic fragility of erythrocytes during exercise, and then the factors in and physiological meaning of the changes in the fragility of cells in athletic horses during exercise will be summarized.

\section{Generality}

\section{Fragility increased factors}

It has been reported that the fragility of erythrocytes from in man, the rat and/or the dog was increased by physical and chemical stress during exercise $[7,12,14$, $17,34,35,38,39,42,59,61,63-65,67,74]$. The physical stress is a result of increases in friction and collision between the red cell membrane and blood vessels [7, 14], and the shear rate of the flowing blood [12]. The causes of this type of physical stress are haemoconcentration due to the loss of water from the vascular compartment because of fluid shifts and sweating and/or the release of splenic red cells into the circulation, an increase in blood flow caused by acceleration of the heart beat, and the physical pressure of capillary blood vessels [17, 34, 74].

Chemical stresses refer to the release of lysolecithin, which gains surface activity from the spleen caused by increased secretion of adrenaline [59, 63, 64], decrease in blood $\mathrm{pH}$ caused by an increase in carbon dioxide partial pressure $\left(\mathrm{PCO}_{2}\right)$ in the blood, respiratory acidosis [61 and the accumulation of blood lactate, metabolic acidosis [35, 38], and the increase in active oxygen (radical-scavenger) and peroxide: hydrogen peroxide and malondialdehyde which deplete the antioxidant, alfa-tocopherol, ascorbate, beta-carotene, bilirubin, reduced glutathione, ubiquinone and uric acid, and damage the erythroid membrane protein and lipids [15, 59, 65]. Maximal exercise induces an increase in the osmotic fragility of human erythrocytes and swelling of the cells. These exercise-induced cellular responses could be simulated in vitro by treating blood with lactic acid, but not by a low $\mathrm{pH}$ or lactate alone [67]. Kogawa et al. [39] suggested that a high concentration of unsaturated fatty acid in the erythroid membrane and hyperthermia caused an increase in the osmotic fragility of rabbit erythrocytes. And Kuypers et al. [42] suggested that the displacement of phospholipids, particularly phosphatidylcholine from native phospholipids to bovine liver, increased the osmotic fragility in rabbit and horse erythroid membranes.

An important point to remember is that the existence of the spleen is related to the increase in the fragility of erythrocytes, as well as to the physical stress and chemical stress that is incurred as a result of exercise. Shiraki [63] observed that a splenectomy increased the osmotic resistance of canine red cells, and the fragility of red cells from normal dogs was greatly increased by exercise, whereas that which was from splenectomized dogs was not changed. He [63] therefore thought that the spleen was the main cause of exercise stress sensitivity of the erythroid membrane.

\section{Fragility decreasing factors}

Smith et al. [66] reported that the osmotic fragility of human erythrocytes decreased immediately after $1 \mathrm{hr}$ of cycling at $60 \%$ of maximum aerobic capacity $\left(\dot{\mathrm{V}} \mathrm{O}_{2} \max \right)$.

Streuli et al. [73] suggested that various cholesterols are the most potent inhibitors of osmotic lysis in human erythrocytes. They [73] observed that oxygenated sterol compounds inserted into the erythroid membrane diminished the osmotic fragility of human erythrocytes in an in vitro condition. Steroid hormones such as corticoid decrease the osmotic fragility of erythrocytes in both in vivo and in vitro conditions [74]. Under in vitro conditions, $\mathrm{pH}$ and temperature have an inverse correlation to the osmotic fragility of erythrocytes in several mammal species and in poultry, such as goats, guinea pigs, man, rats, sheep, domestic fowls and guinea-fowls [36, 48, 50-52, 54]. The decrease in the osmotic fragility of erythrocytes from the above animals and increased $\mathrm{pH}$ and temperature could be due to changes in the membrane lipids and proteins. But Giger et al. [21] suggested that the fragility of inherited phosphofructokinase deficient erythrocytes from dogs increased in both in vivo and in vitro alkaline conditions. Kogawa et al. [39] observed that hyperthermia caused an increase in intracellular water and a decrease in the osmotic resistance of rabbit erythrocytes.

Tesoriere et al. [75] reported that melatonin 
Table 1. The comparison of the influence of exercise on erythrocyte indices and osmotic fragility of erythrocytes in athletic horses

\begin{tabular}{|c|c|c|c|c|}
\hline References No. & $4-6,45$ & 18,68 & \multicolumn{2}{|c|}{$25-29$} \\
\hline Exercise $^{1)}$ & High & High & Low & High \\
\hline $\mathrm{MCV}^{2)}$ & Decrease & Increase & Decrease & Increase \\
\hline $\mathrm{MCHC}^{3)}$ & Increase & Decrease & No change & Decrease \\
\hline Echinocyte & Increase & No change & No change & No change \\
\hline $\mathrm{OFE}^{4)}$ & Increase & Decrease & Decrease & Increase \\
\hline
\end{tabular}

1) High: high intensity exercise; Low: low intensity exercise; 2) mean cell volume;

3) mean cell haemoglobin concentration; 4) osmotic fragility of erythrocytes.

inhibited the formation of membrane protein carbonyls and hemin precipitation by cumene hydroperoxide in an in vitro treatment.

\section{Athletic horses}

As shown in Table 1, reports of changes in the osmotic fragility of equine erythrocytes during exercises vary according to the researcher. We examined these contradictory results from various points of view.

\section{Exercise intensity}

Sakurai et al. [62] reported that the osmotic fragility of erythrocytes in Thoroughbreds progressively increased with the running velocity of short distance field exercises: at $6.7 \mathrm{~m} / \mathrm{sec}$ for $1,100 \mathrm{~m}, 11.1 \mathrm{~m} / \mathrm{sec}$ for $1,100 \mathrm{~m}$, and $12.5 \mathrm{~m} / \mathrm{sec}$ for $1,600 \mathrm{~m}$. Murakami [49] observed intravascular haemolysis in Thoroughbreds during long distance field exercise. Boucher [5] suggested that the osmotic fragility of erythrocytes in Thoroughbreds increased with short speed-running workouts. The osmotic fragility of erythrocytes and plasma haemoglobin concentration in Thoroughbreds also significantly increased after maximal exercise for a distance of 1,000 $\mathrm{m}$ on a sand track [31].

Nevertheless, Smith et al. [68] reported that highspeed exercise for a short distance on a treadmill (at 10 $\mathrm{m} / \mathrm{sec}$ for $2 \mathrm{~min}$ on a $3.3 \%$ incline) significantly decreased the fragility of erythrocytes in Quarterhorses and Thoroughbreds. Hanzawa et al. [24] observed that aerobic exercise (at 9 or $10 \mathrm{~m} / \mathrm{s}$ ) significantly decreased the osmotic fragility of erythrocytes measured as the haemolysis rate in $0.56 \%$ sodium chloride $\left(\mathrm{HL}_{0.56}\right)$ in Thoroughbreds, but anaerobic exercise (at 13 or $15 \mathrm{~m} / \mathrm{s}$ over) significantly increased the $\mathrm{HL}_{0.56}$ for a distance of $800 \mathrm{~m}$ on a sand track. They also investigated the sequential changes in the osmotic fragility of erythrocytes $\left(\mathrm{HL}_{0.56}\right)$ in Thoroughbreds during low and/or high intensity treadmill-exercise [27]. As shown in Fig. 1, previous warming up at $2 \mathrm{~m} / \mathrm{s}$ for $2 \mathrm{~min}, 4 \mathrm{~m} / \mathrm{s}$ for $5 \mathrm{~min}$ and then $2 \mathrm{~m} / \mathrm{s}$ for $5 \mathrm{~min}$ ( $0 \%$ incline) significantly decreased the $\mathrm{HL}_{0.56}$, and cantering at $8 \mathrm{~m} / \mathrm{s}$ for $8 \mathrm{~min}(10 \%$ incline) significantly increased the $\mathrm{HL}_{0.56}$; subsequent cooling down at 4-2 $\mathrm{m} / \mathrm{s}$ for $20 \mathrm{~min}(0 \%$ incline $)$ significantly decreased the $\mathrm{HL}_{0.56}$, but thereafter the $\mathrm{HL}_{0.56}$ gradually increased again, returning to the initial resting level. In contrast, continuous trotting at $5 \mathrm{~m} / \mathrm{s}$ for $15 \mathrm{~min}$ ( $0 \%$ incline) significantly decreased the $\mathrm{HL}_{0.56}$ [27]. Moreover, they exercised on the treadmill for three 5 min periods at 5 incremental speeds, ranging from $80-120 \% \mathrm{~V}_{\mathrm{LA4}}$ which was increased $10 \% \mathrm{~V}_{\mathrm{LA} 4}$ every min with a 5 min rest between each period for the Thoroughbreds. The $\mathrm{HL}_{0.56}$ during the resting period between each exercise period was decreased by the exercise, but the $\mathrm{HL}_{0.56}$ increased with an increase in speed and had an upward tendency as the exercise intensified [26].

These results suggest that anaerobic exercise increases the osmotic fragility of erythrocytes, but aerobic exercise decreases the fragility in athletic horses.

\section{Spleen and splenectomy-the opposing opinion-}

The splenic contractile response under adrenergic stimulation of the horse is perhaps more sensitive than that of any other species. Up to a $50 \%$ increase in the population of equine red cells in circulation during exercise is a result of the mobilization of the cells from the spleen [55]. Boucher $[4,5]$ suggested that exercise increased the fragility of erythrocytes in the horse due to the release of fragile cells as shrinkage crenated red cells (echinocytes) from the spleen into the circulation. It is proposed that the stagnant, hypoxic conditions in the spleen promote the adenosine triphosphate (ATP) 


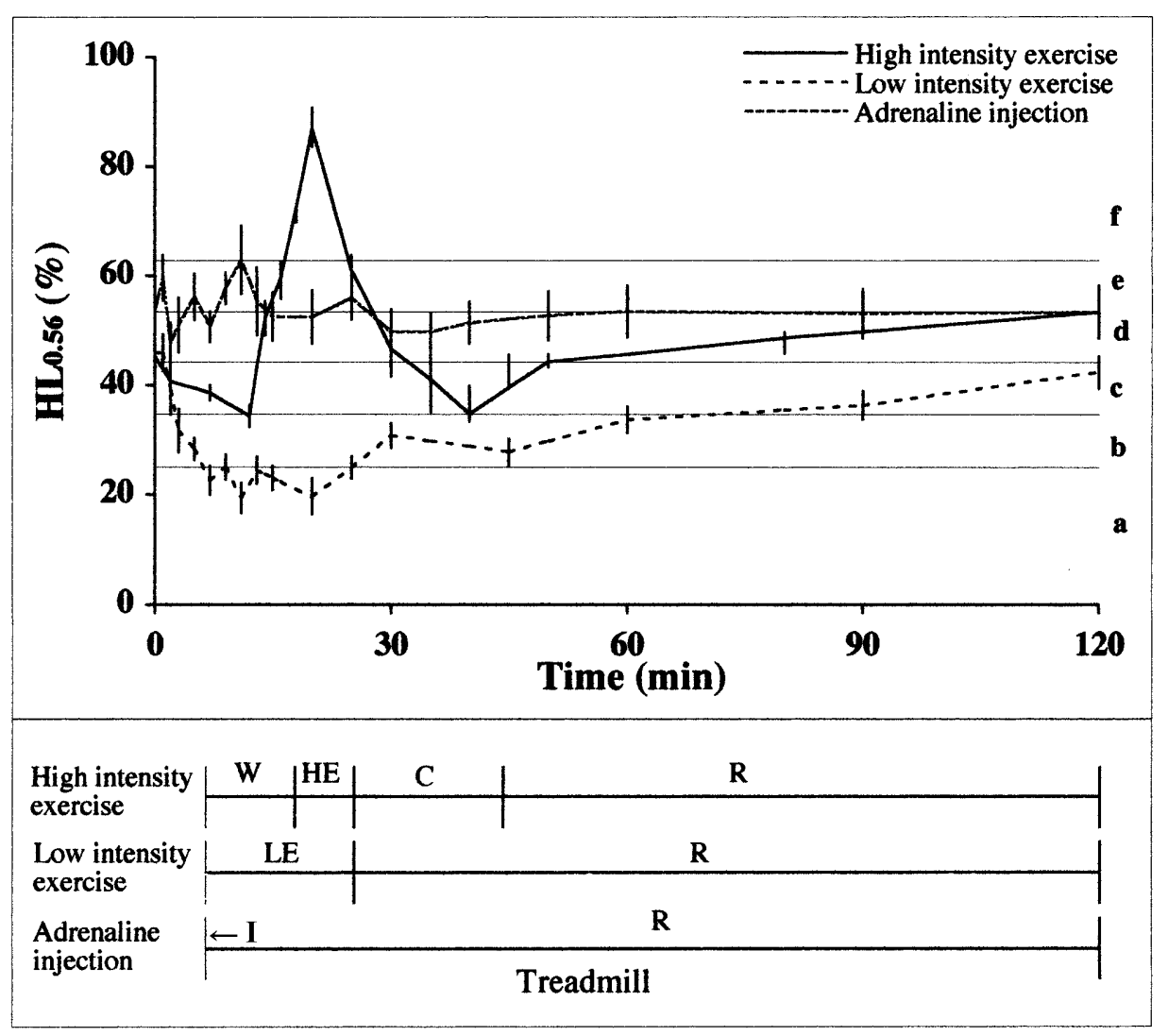

Fig. 1. Changes (mean \pm s.e.m.) in osmotic fragility of erythrocytes measured as the haemolysis rate in $0.56 \%$ sodium chloride $\left(\mathrm{HL}_{0.56}\right)$ during high and low intensity exercise, and after adrenaline injection in Thoroughbred horses. Scott \& Knott's cluster analysis : $a<b<c<d<e<f$, $\mathrm{P}<0.05$. W: warming up; HE: high intensity exercise; C: cool-down; R: rest; LE: light exercise; $\leftarrow$ I: Adrenaline injection (Modified from Hanzawa et al. [27]).

depletion of cells, leading to the formation of echinocytes. This phenomenon may be related to the failure of oxygen delivery, and could produce pathophysiologic conditions related to exertion, such as exercise-induced pulmonary hemorrhage (EIPH), exertional myopathy (tying-up syndrome) and certain orthopedic diseases [4, 77]. McClay et al. [45] also reported that competitive racing increased the number of echinocytes, but decreased the red cell volume of Thoroughbreds.

But this hypothesis has been based on indirect evidence. Snow and Martin [69] suggested that the ATP content in circulating erythrocytes of Thoroughbreds and/or mixed breed ponies was decreased by exercise and/or by adrenaline injections, regardless of the release of red cells from the spleen into the circulation. Minimal changes in the number of echinocytes and a significant decrease in the osmotic fragility of erythrocytes were also found in treadmillexercised Quarterhorses and Thoroughbreds from which samples were drawn immediately after exercise [68]. Hanzawa et al. [26] observed that the osmotic fragility of erythrocytes was significantly increased and decreased by repetition, but the mean percentage of red cells circulating as echinocytes did not change during three repetitive loads of incremental exercise. Geor et al. [18] suggested that only systemic electrolyte depletion might be involved in the induction of echinocyte formation. They [18] also reported that during exercise, a significantly greater proportion of the erythrocytes were less dense and were found in the upper layers of the red cell density gradient profile, as compared with the resting values of the Thoroughbreds.

Intravenous injection of adrenaline $(2.5 \mu \mathrm{g} / \mathrm{kg}$ body weight) to Thoroughbreds significantly increased the haematocrit value in the peripheral blood, but it had 

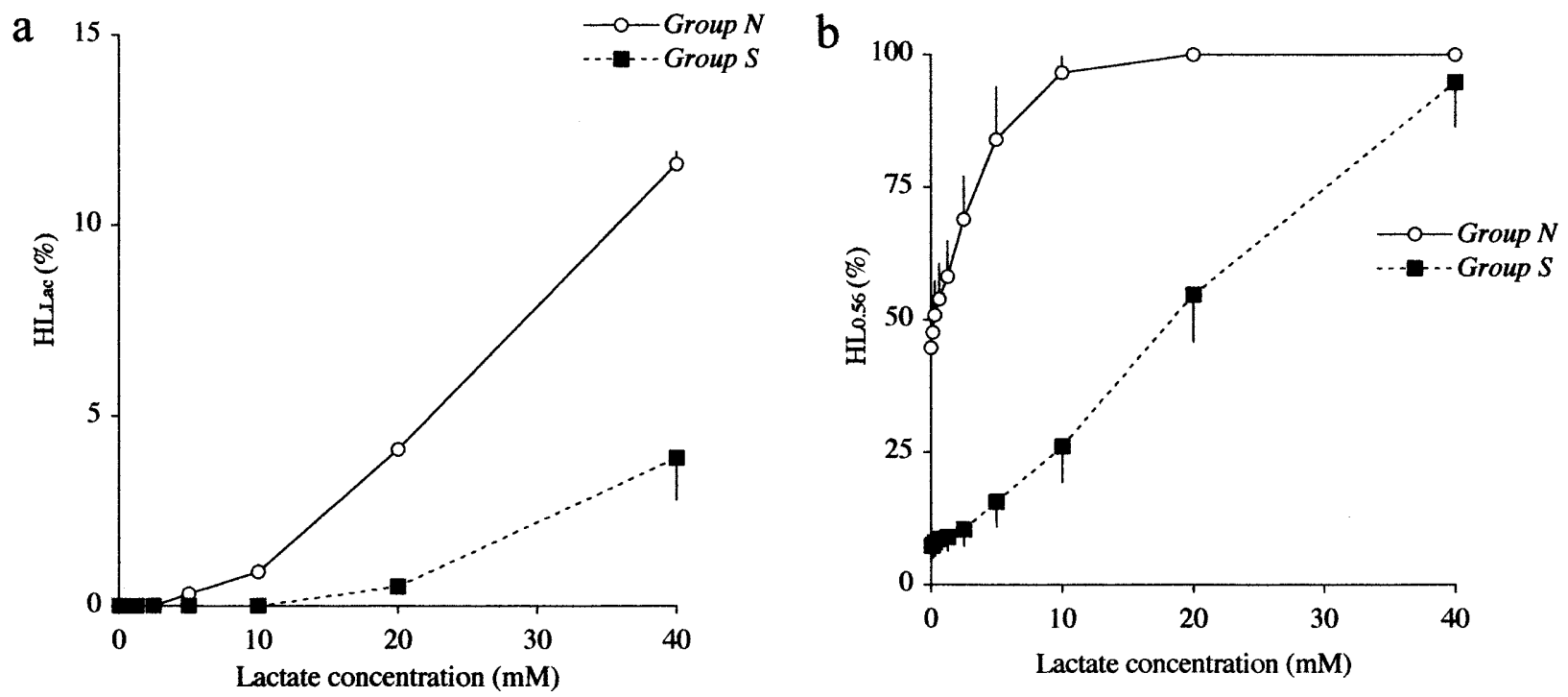

Fig. 2. Effect of exposure to lactate solution on haemolysis rare $\left(\mathrm{HL}_{\mathrm{Lac}}\right)$ : a, and on osmotic fragility of erythrocytes measured as the haemolysis rate in $0.56 \%$ sodium chloride $\left(\mathrm{HL}_{0.56}\right)$ : b, in normal (Group $N: \bigcirc$ ) and splenectomised (Group $\left.S: \mathbf{\square}\right)$ Thoroughbred horses (Hanzawa, K., Kubo, K., Kai, M., Hiraga, A., and Watanabe, S., Unpublished data).

little effect on the osmotic fragility of circulating erythrocytes (Fig. 1) [27]. The osmotic fragility of circulating erythrocytes was lower than that of the autologous splenic red cells in the Thoroughbreds, and it gradually decreased 2 months after the splenectomy [28]. The haemolysis rate of the circulating erythrocytes due to lactate treatment $\left(\mathrm{HL}_{\mathrm{Lac}}\right)$ in the splenectomized horses was significantly lower than that in normal horses (Fig. 2a). In normal horses, the $\mathrm{HL}_{0.56}$ of the lactate treated erythrocytes significantly increased the concentration dependence of lactate, when the lactate concentration was used for cell treatment in a range between 0.15625 and $10 \mathrm{mM}$. The $\mathrm{HL}_{0.56}$ in splenectomized horses increased in the same manner as in normal horses caused by an increase in treating the lactate concentration, but the $\mathrm{HL}_{0.56}$ in the splenectomized horses was significantly lower than in the normal horses regardless of lactate treatment (Fig. 2b) (Hanzawa et al. unpublished data). $\mathrm{HL}_{0.56}$ in both the normal and splenectomized horses significantly decreased with warming up exercises at $4 \mathrm{~m} / \mathrm{s}$ for $5 \mathrm{~min}$ (at $0 \%$ incline), but significantly increased with cantering and galloping at 3 to 4 incremental speeds until the point of fatigue: ranging $80-100 \%$ peak speeds for 4-5 min (at 7\% incline), and decreased again with a cooling down at $4-2 \mathrm{~m} / \mathrm{s}$ for $20 \mathrm{~min}$ (at $0 \%$ incline) [25, 27]. Moreover, except after the incremental exercise in normal horses, erythrocytes in both the normal and splenectomized horses were swelled by washing with PBS, regardless of the exercise. Warming up exercises did not change the density of the PBS washed erythrocytes in either the normal or the splenectomized horses. In contrast, incremental exercise significantly increased the density of the PBS washed erythrocytes in normal horses due to the activation of regulatory volume decreases, but not in splenectomized horses [25, 29]. Kunugiyama et al. [41] suggested that blood stored in the Thoroughbred spleen is gradually mixed with the circulating blood, and it was clarified that this phenomenon was completed within $2 \mathrm{hr}$.

Our research therefore suggests that: 1) frequent accumulation in the spleen accelerates the osmotic fragility, the decreasing regulatory volume and the lactate and/or $\mathrm{pH}$ susceptibility of equine erythrocytes; and 2) The release of erythrocytes from the spleen into the circulation has no effect on changes in the fragility during exercise.

\section{Blood $p H$ and temperature}

Under in vitro conditions, $\mathrm{pH}$ and temperature have an inverse correlation to the osmotic fragility of erythrocytes in several mammal species and in poultry, with exception of the $\operatorname{dog}[21,36,48,50-52,54]$. Anaerobic exercise usually increases the carbon dioxide partial pressure $\left(\mathrm{PCO}_{2}\right)$ and the lactate 


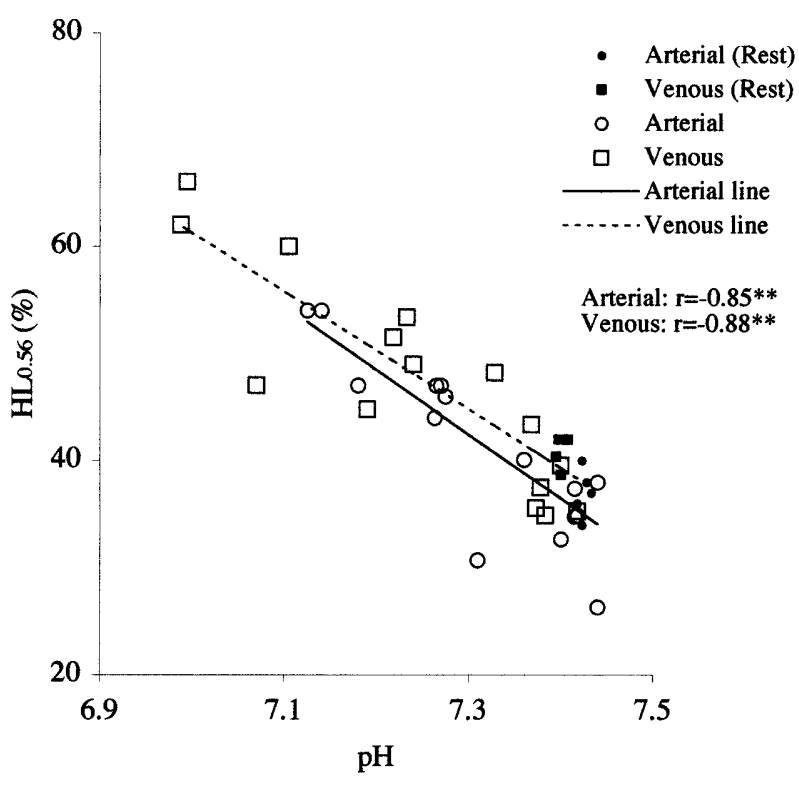

Fig. 3. Relationship between blood $\mathrm{pH}(\mathrm{pH})$ and osmotic fragility of erythrocytes measured as the haemolysis rate in $0.56 \%$ sodium chloride $\left(\mathrm{HL}_{0.56}\right)$ during exercise in Thoroughbred horses. Arterial (Rest) : arterial blood at rest, Venous (Rest): venous blood at rest, Arterial and venous: arterial and venous blood during exercise, and Arterial and venous lines: regression line between arterial and venous blood $\mathrm{pH}$ and $\mathrm{HL}_{0.56}$ (Modified from Hanzawa et al. [23]).

concentration in the blood, but decreases the bicarbonate ion concentration $\left(\mathrm{HCO}_{3}{ }^{-}\right)$in the blood, and then decreases the blood $\mathrm{pH}[11,40]$. Bayly et al. [1] and Pan et al. [53] suggested that aerobic exercise increases blood pH; i.e., an increase in blood temperature during prolonged submaximal exercise on a treadmill stimulated ventilatory responses, thus increasing the blood $\mathrm{pH}$.

Hanzawa et al. [23] examined the relationship between $\mathrm{HL}_{0.56}$ and 10 physiological characteristics: heart rate, haematocrit, haemoglobin, mean cell haemoglobin concentration, $\mathrm{PCO}_{2}$, oxygen partial pressure $\left(\mathrm{Po}_{2}\right)$, and $\mathrm{HCO}_{3}^{-}$, lactate concentration, $\mathrm{pH}$ and temperature of the blood during exercise in Thoroughbreds. The animals were exercised on a treadmill: warmed up at $30 \% \dot{\mathrm{V}} \mathrm{O}_{2}$ max for 5 min or at $105 \% \dot{\mathrm{V}} \mathrm{O}_{2} \max$ for $1 \mathrm{~min}$, given an exercise test at $80 \%$ or $105 \% \dot{\mathrm{VO}_{2}}$ max until fatigued, and then cooled down. The simple correlation coefficient between the blood $\mathrm{pH}$ and the $\mathrm{HL}_{0.56}$ showed the highest value in correlations of all the measured physiological factors for $\mathrm{HL}_{0.56}: \mathrm{r}=-0.85$ and $-0.88 \mathrm{in}$ arterial and mixed

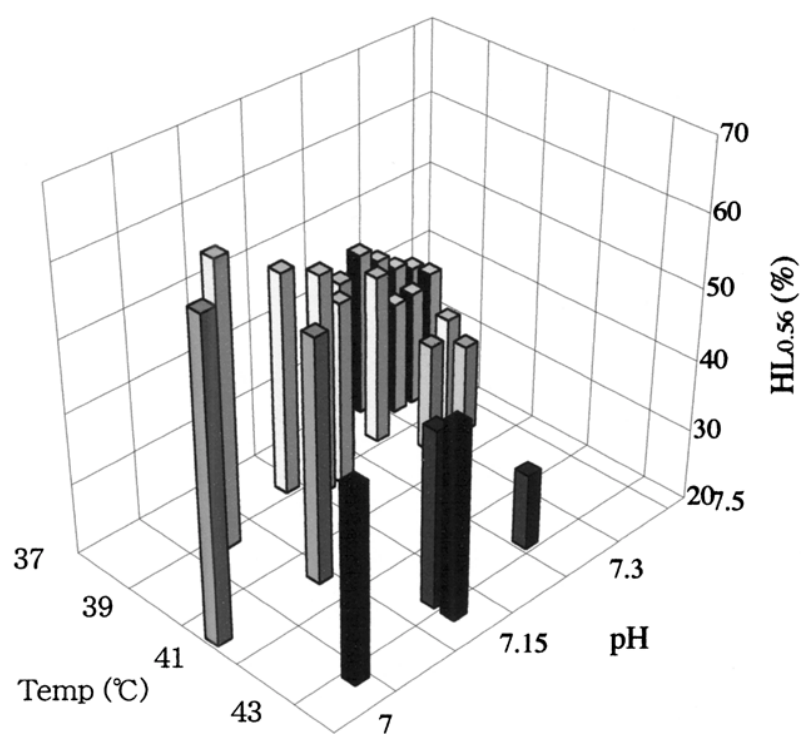

Fig. 4. Relationship between $\mathrm{pH}$ and temperature (Temp) of blood and osmotic fragility of erythrocytes measured as the haemolysis rate in $0.56 \%$ sodium chloride $\left(\mathrm{HL}_{0.56}\right)$ during exercise in Thoroughbred horses. (Modified data from Hanzawa et al. [23]).

venous blood, respectively $(\mathrm{P}<0.01)$ (Fig. 3). In multiple regression analysis, $\mathrm{PcO}_{2}, \mathrm{HCO}_{3}^{-}$, blood $\mathrm{pH}$ and temperature showed significant correlations with $\mathrm{HL}_{0.56}$, whereas the heart rate, haematocrit and haemoglobin showed lower correlations with $\mathrm{HL}_{0.56}$. The $\mathrm{pH}$ and temperature of the blood had a significant multi correlation coefficient for $\mathrm{HL}_{0.56}: \mathrm{r}=0.93$ and 0.92 in arterial and mixed venous blood, respectively $(\mathrm{P}<0.01)$ (Fig. 4) [23]. $\mathrm{HL}_{0.56}$ of mixed venous blood was increased by treatment with an acid solution (lactate), but was decreased by an alkali solution $(\mathrm{NaOH})$. The correlation between the medium $\mathrm{pH}$ and $\mathrm{HL}_{0.56}$ in the in vitro condition was significant: $\mathrm{r}=-$ $0.93(\mathrm{P}<0.01)$ [22].

These results suggest that in exercising horses: 1) the increase in blood flow and the release of erythrocytes from the spleen into the circulation have little effect on changes in the osmotic fragility of erythrocytes; 2) the decrease in blood $\mathrm{pH}$ promotes the osmotic fragility of erythrocytes; 3 ) the increase in $\mathrm{pH}$ causes osmotic resistance in the cells; and 4) an increase in blood temperature during exercise is associated with a decrease in the osmotic fragility of erythrocytes.

4. Other factors - possible factors in fragility reducible

$\mathrm{K}-\mathrm{Cl}$ cotransporter: Erythrocytes from horses contain 
high intracellular levels of $\mathrm{K}^{+}$, although $\mathrm{K}^{+}$transport across their membranes is dominated by a high capacity of $\mathrm{K}-\mathrm{Cl}$ cotransporter [19, 20]. This transporter is sensitive to cell volume, $\mathrm{pH}$ and $\mathrm{Po}_{2}[19,70]$. Hanzawa et al. [22] observed that K-Cl cotransporter of erythrocytes from Thoroughbreds was stimulated by lowering the external osmotic pressure and/or $\mathrm{pH}$, but was inhibited by raising the external osmotic pressure and/or $\mathrm{pH}$. The increase in cell density was associated with a progressive increase in $\mathrm{K}-\mathrm{Cl}$ cotransport activity and the decrease in $\mathrm{HL}_{0.56}$. The increase in density of the erythrocytes in Thoroughbred horses at rest was associated with an increase in $\mathrm{K}-\mathrm{Cl}$ cotransport activity which increased according to the in vivo aging of the red cells, but the osmotic fragility of erythrocytes decreased [31] (Hanzawa et al. unpublished data).

Maximal exercise induced an increase in the volume and fragility of erythrocytes from humans and horses [29, 45, 67]. Light et al. [44] suggested that the osmotic fragility which increases with the inhibition of protein kinase $\mathrm{C}$ stimulates $\mathrm{K}^{+}$efflux during regulatory volume decreases in mudpuppy red cells in man. These results suggest that the K-Cl cotransporter in the equine erythrocytes has a functional interrelation to the fragility.

Bilirubin: Stocker et al. [72] suggested that plasma bilirubin has antioxidant activity. Exercise increased equine plasma bilirubin, which has antioxidant activity as well [60]. Kuwabara et al. [43] suggested that albumin-bound bilirubin was one of the reasons for the high superoxide-scavenging ability of serum in Thoroughbred horses.

L-Carnitine: 3-hydroxy-4- $N$-trimethylammonium butyric acid (L-carnitine) assists in the regulation of the acetylCoA/CoA ratio by buffering excess acetylCoA production in muscle [16]. L-Carnitine increases the uptake of structural lipids, which could also lead to higher stability of cell membranes [2,3], but the Lcarnitine concentration in equine plasma was not changed by exercise [16].

Lactate: Robin and Harley [58] and Medeiros et al. [47] suggested that lactate was frequently utilized to produce NADH which reduced methaemoglobin (metHb) in equine erythrocytes during in vitro conditions. A slight increase in plasma lactate with low intensity exercise may reduce intracellular metHb, thus promoting the osmotic resistance of erythrocytes, but lactate at lower concentrations than in plasma increased the osmotic fragility of equine erythrocytes [22] (see Fig. 2b).

\section{Indicator of athletic performance}

Intravascular haemolysis: Hanzawa et al. [26, 30-32] observed that the increase in the concentration of haemoglobin binds to haptoglobin in the plasma followed by an increase in the osmotic fragility of erythrocytes from Thoroughbreds after maximal exercise on a sand track, single high intensity exercise and three repetitive loads of incremental exercise on a treadmill, so that the osmotic fragility of erythrocytes in athletic horses is an important clinical indicator of intravascular haemolysis during exercise.

Exercise capacity: Hanzawa et al. [24] compared the osmotic fragility of erythrocytes in aerobic trained horses (Group Aer) and anaerobic trained horses (Group $A n a)$. The velocity for a blood lactate concentration of $4 \mathrm{mmol} / \mathrm{l}$ in Group Ana was slightly higher than in Group Aer for a distance of $800 \mathrm{~m}$ on a sand track. An increase in blood lactate during aerobic exercise in Group Aer horses was not associated with changes in red cell membrane fragility, but in Group Ana it was correlated with a progressive decrease in fragility. These results suggested that Group Ana horses might improve more in their respiration and circulation at low intensity exercise than Group Aer, so that the osmotic fragility of erythrocytes could be an indicator of athletic performance.

\section{Conclusion}

Knowledge of the effects of exercise on the osmotic fragility of erythrocytes in athletic horses is assembled as shown in Table 2. Aerobic exercise increases the temperature and/or $\mathrm{pH}$ of the blood, shrinks the equine erythrocytes due to changes in the lipid composition and protein structure of the cell membrane, and then decreases the osmotic fragility of the erythrocytes $[1,22,23,52,66,68]$, whereas anaerobic exercise decreases blood $\mathrm{pH}$, swells the erythrocytes due to changes in lipid composition and the protein structure of the cell membrane, and then increases the osmotic fragility of the cells caused by oxidative damage to the cell membrane protein and lipids [22, 23, 52, 66, 67]. K-Cl cotransporter of equine erythrocyte membrane is activated by lowering the extracellular $\mathrm{pH}$ and/or increasing external oxygen, and inhibits the swelling of the red cells during exercise $[19,22,70]$. An increase in echinocytes, which was observed at times during and after exercise, may occur due to the decrease in intracellular ATP, an increase in 
Table 2. The effect of exercise on membrane fragility of erythrocytes in athletic horses

\begin{tabular}{llll}
\hline \multicolumn{1}{c}{ Exercise } & \multicolumn{1}{c}{ Aerobic } & Anaerobic & \multicolumn{1}{c}{ References } \\
\hline Cell volume & Decrease & Increase & $18,66-68$ \\
Density & Decrease & Increase & 18,68 \\
Echinocyte & Small increase & No change & $18,26,68$ \\
Blood pH & No change or rise & Fall & $1,11,23,40,53$ \\
Blood temperature & Rise & Rise & $1,11,23$ \\
Fragility & Decrease & Increase & $22-28,52$ \\
\hline
\end{tabular}

blood $\mathrm{pH}$ and/or activation of $\mathrm{K}-\mathrm{Cl}$ cotransporter [5, 19, 45, 69].

Osmotic fragility of erythrocytes in athletic horses is an indicator of the training effect and/or athletic performance, particularly acid-base responses, and exercise stress [23, 24]. The release of erythrocytes from the spleen into the circulation has little effect on changes in the osmotic fragility of erythrocytes, but frequent accumulation in the spleen accelerates osmotic fragility, regulatory volume decreases and lactate and/or $\mathrm{pH}$ susceptibility of equine erythrocytes [22, 28] (unpublished data, as shown in Fig. 2).

Providing erythrocyte destruction during exercise does not exceed the rate of red cell production, no detrimental effect on athletic performance should occur. An increased rate of erythrocyte turnover may be advantageous because young cells are more efficient in transporting oxygen [65].

Although a decrease in circulating erythrocytes is sometimes observed during the training term of young horses, there are few reports regarding sport anemia in athletic horses $[37,46]$. Polycythaemia is rather more often reported in racehorses that are fully trained [56, 71]. Watanabe et al. [76] observed that erythroid burstforming units (BFU-E) and/or erythroid colonyforming units (CFU-E) in the peripheral blood maturated promptly in the erythroblasts in horse serum containing medium in place of fetal calf serum (FCS) without recombinant erythropoietin.

Because haematopoiesis is very high, the possibility that haemolysis caused by an increase in fragility during exercise causes anemia could be unlikely in view of the above knowledge of athletic horses. Therefore, haemolysis with exercise has an active function which rather rejuvenates the erythrocytes in athletic horses.

\section{References}

1. Bayly, W., Schott, H., and Slocombe, R. 1995. Ventilatory responses of horses to prolonged submaximal exercise. Equine vet. J., Suppl. 18: 2328.

2. Bayon, J.E., Alvares, A.I., Barrio, J.P., Diez, C., and Prieto, J.G. 1993. Effects of stanozolol and Lcarnitine on erythrocyte osmotic fragility during aerobic exercise in rats. Comp. Haematol. Int. 3: 196-200.

3. Bennett, M.J. and Boriack, R.L. 1995. Erythrocyte membrane reacylation in juvenile neuronal ceroid-lipofuscinosis: measurement of membranebound carnitine palmitoyl transferase, acyl-CoA synthetase, and lysophospholipid: acyl-CoA acyltransferase activities. Am. J. Med. Genet. 57: 304-306.

4. Boucher, J.H. 1987. The equine spleen: Source of dangerous red blood cells. J. Equine Vet. Sci. 7: 140142.

5. Boucher, J.H. 1989. The Role of Blood in Equine Performance, Exercise-Induced Echinocytes. pp. 43-52. In: Equine Sports Medicine. (William, E.J. eds.) Lea \& Febiger, Philadelphia.

6. Boucher, J.H., Ferguson, E.W., Wilhemsen, C.L., Statham, N., and McMeekin, R.R. 1981. Erythrocyte alteration during endurance exercise in horses. J. Appl. Physiol. 51: 131-134.

7. Broun, G.O. 1922. Blood destruction during exercise. I. Blood changes occurring in the course of a single day of exercise. J. Exper. Med. 36: 481500.

8. Broun, G.O. 1923. Blood destruction during exercise. II. Demonstration of blood destruction in animals exercised after prolonged confinement. J. Exper. Med. 37: 113-130.

9. Broun, G.O. 1923. Blood destruction during exercise. III. Exercise as a bone marrow stimulus. J. Exper. Med. 37: 187-206.

10. Broun, G.O. 1923. Blood destruction during 
exercise. IV. The development of equilibrium between blood destruction and regeneration after a period of training. J. Exper. Med. 37: 207-220.

11. Carlson, G.P. 1995. Interrelationships between fluid electrolyte and acid-base balance during maximal exercise. Equine Vet. J., Suppl. 18: 261265.

12. Chien, S. and Lipowsky, H.H. 1982. Correlation of hemodynamics in macrocirculation and microcirculation. Int. J. Microcirc. Clin. Exp. 1: 351365.

13. Davis, J.E. and Brewer, N. 1953. Effect of physical training on blood volume, hemoglobin, alkali reserve and osmotic resistance of erythrocytes. J. Apple. Physi. 9: 586-591.

14. Davidson, R.J.L. 1964. Exertional haemoglobinuria. A report on three cases with studies on the haemolytic mechanism. J. Clin. Pathol. 17: 536540.

15. Fich, C.D., Chevli, R., Kanjananggulpan, P., Dutta, P., Chevli, K., and Chou, A.C. 1983. Intercellular ferriprotoporphyrin IX is a lytic agent. Blood 62: 1165-1168.

16. Foster, C.V.L. and Harris, R.C. 1987. Changes in free and bound carnitine in muscle with maximal sprit exercise in the Thoroughbred horse. Equine Exercise Physiology 2: 332-340.

17. Gauer, O.H., Henry, J.P., and Behn, C. 1970. The regulation of extracellular fluid volume. Ann. Rev. Physiol. 32: 547-595.

18. Geor, R.J., Weiss, D.J., and Smith II, C.M. 1994. Hemorrheologic alterations induced by incremental treadmill exercise in Thoroughbreds. Am. J. Vet. Res. 55: 854-861.

19. Gibson, J.S., Ellory, J.C., Culliford, S.J., and Fincham, D.A. 1993. Volume-sensitive KCl cotransport and taurine fluxes in horse red blood cells. Exp. Phys. 78: 685-695.

20. Gibson, J.S., Godart, H., Ellory, J.C., Staines, H., Honess, N.A., and Cossins, A.R. 1995. Modulation of $\mathrm{K}^{+}-\mathrm{CL}^{-}$cotransport in equine red cells. Exp. Phys. 79: 997-1009.

21. Giger, U., Harvey, J.W., Yamaguchi, R.A., McNulty, P.K., Chiapella, A., and Beutler, E. 1985. Inherited phosphofructokinase deficiency in dogs with hyperventilation-induced homeless: increased in vitro and in vivo alkaline fragility of erythrocytes. Blood 65: 345-351.

22. Hanzawa, K., Fujise, H., and Watanabe, S. 1998. Effects of $\mathrm{pH}$ on osmotic fragility and K-Cl cotransport in equine red blood cells. pp. 128. In: Proceedings of The 1998 Congress of The
International Society for Animal Clinical Biochemistry. Hiroshima, Japan.

23. Hanzawa, K., Kai, M., Hiraga, A., and Watanabe, S. 1999. Fragility of red cells during exercise is affected by blood $\mathrm{pH}$ and temperature. Equine Vet. J., Suppl. 30: 610-611.

24. Hanzawa, K., Kubo, K., Hiraga, A., and Watanabe, S. 1996. Correlation between field exercise intensity and osmotic fragility of erythrocytes in thoroughbred horses. pp. 574-575. In: The Proceedings of the 8th Animal Science Congress of the Asian-Australasian Association of Animal Production Societies. Vol. 2. Chiba, Japan.

25. Hanzawa, K., Kubo, K., Kai, M., Hiraga, A., and Watanabe, S. 1995. Effects of exercise on erythrocytes in normal and splenectomised Thoroughbred horses. Equine Vet. J., Suppl. 18: 439-442.

26. Hanzawa, K., Kubo, K., Kai, M., Hiraga, A., and Watanabe, S. 1996. Effects of three repetitive loads of incremental exercise on circulating erythrocytes in Thoroughbred horses. Pferdeheikunde 12: 502-505.

27. Hanzawa, K., Kubo, K., Kai, M., Hiraga, A., and Watanabe, S. 1998. Effects of splenic erythrocytes and blood lactate levels on osmotic fragility of circulating red cells in Thoroughbred horses during exercise. J. Equine Sci. 9: 107-112.

28. Hanzawa, K., Kubo, K., Kai, M., Hiraga, A., and Watanabe, S. 1999. Effects of the splenectomy on osmotic fragility of circulating red cells in Thoroughbred horses during exercise. J. Equine Sci. 10: 61-65.

29. Hanzawa, K., Kubo, K., Kai, M., Hiraga, A., and Watanabe, S. 1999. Effects of exercise on density and osmotic fragility of circulating red cells in normal and splenectomized Thoroughbred horses. J. Equine Sci. 10: 67-72.

30. Hanzawa, K., Kubo, K., Kai, M., Hiraga, A., and Watanabe, S. 2000. Effects of exercise on plasma haptoglobin composition in control and splenectomized Thoroughbred horses. pp. 137140. In: The Elite Show Jumper. Conference on Equine Sports Medicine and Science 2000. (Lindner, A. eds.) Sicily, Italy.

31. Hanzawa, K., Orihara, K., Kubo, K., Yamanobe, A., Hiraga, A., and Watanabe, S. 1992. Changes of plasma amino acid and inorganic ion concentration with maximum exercises in Thoroughbred young horses. Jpn. J. Equine Sci. 3: 157-162.

32. Hanzawa, K., Orihara, K., Kubo, K., Kai, M., 
Hiraga, A., and Watanabe, S. 2000. Changes of two-dimensional electrophoretic patterns of plasma proteins with maximum exercises in young Thoroughbred horses. Asian-Australassian J. Anim. Sci. 13, Suppl. A: 152-155.

33. Hanzawa, K., and Watanabe, S. 1995. Physiological characterization of density-separated Thoroughbred horse erythrocytes. J. Equine Sci. 6: 61-66.

34. Harrison, M.H. 1985. Effects of thermal stress and exercise on blood volume in humans. Physiol. Rev. 65: 149-207.

35. Hiro, T. 1982. Studies on the osmotic fragility of erythrocytes influenced by a metabolic acidosis. $J$. Physical Fitness Jpn. 31: 279-290 (in Japanese).

36. Jacob, M.H. and Parpart, A.K. 1931. Osmotic properties of the erythrocyte. II. The influence of $\mathrm{pH}$, temperature and oxygen tension on haemolysis by hypotonic solutions. Biol. Bullet. 60 : 95-119.

37. Johnson, J.E., Beech, J., and Saik, J.E. 1988. Disseminated hemangiosarcoma in a horse. J. Am. Vet. Med. Assoc. 193: 1429-1431.

38. Keul, I., Keppler, D., and Doll, E. 1967. Standard bicarbonate, $\mathrm{pH}$, lactate and pyruvate concentration during and after muscular exercise. German Med. Month. 12: 156-158.

39. Kogawa, H., Yabushita, N., Nakajima, T., and Kageyama, K. 1998. Studies on in vitro effect of free fatty acids on water content and osmotic fragility of rabbit (Lepus cuniculus) erythrocytes. Life Sci. 62: 823-828.

40. Kronfeld, D.S., Ferrante, P.L., Taylor, L.E., and Custalow, S.E. 1995. Blood hydrogen ion and lactate concentrations during strenuous exercise in the horse. Equine Vet. J., Suppl. 18: 266-269.

41. Kunugiyama, I., Ito, N., Narizuka, M., Kataoka, S., Furukawa, Y., Hiraga, A., Kai, M., and Kubo, K. 1997. Measurement of erythrocyte volumes in splenectomized horses and sham-operated horses at rest and during maximal exercise. J. Vet. Med. Sci. 59: 733-737.

42. Kuypers, F.A., Easton, E.W., Hoven, R., Wensing, T., Roelofsen, B., Kamp, J.A., and Deenen, L.L. 1985. Survival of rabbit and horse erythrocytes in vivo after changing the fatty acyl composition of their phosphatidylcholine. Biochim. Biophys. Acta. 819: 170-178.

43. Kuwabara, M., Inukai, N., Inanami, O., Miyake, Y.I., Tsunoda, N., Maki, Y., and Sato, F. 1996. Lipid peroxide levels and superoxide-scavenging abilities of sera obtained from hotbred
(Thoroughbred) horses. J. Vet. Med. Sci. 58: 97101.

44. Light, D.B., Adler, M.R., Ter, B.J.K., Botsford, S.A., and Gronau, R.T. 1998. Protein kinase C and regulatory volume decrease in mudpuppy red blood cells. J. Membr. Biol. 166: 119-132.

45. McClay, C.B., Weiss, D.J., Smith, C.M., and Gordon, B. 1992. Evaluation of hemorheologic variables as implications for exercise-induced pulmonary hemorrhage in racing Thoroughbreds. Am. J. Vet. Res., 53: 1380-1385.

46. McCoy, D.J. and Beasley, R. 1986. Hypercalcemia associated with malignancy in a horse. J. Am. Vet. Med. Assoc. 189: 87-89.

47. Medeiros, L.O., Nurmberger, R., and Medeiros, L.F. 1984. The special behavior of equine erythrocytes connected with the methemoglobin regulation. Comp. Biochem. Physiol. 78B: 869-871.

48. Moriyama, H. and Oohashi, S. 1947. Reinforcement of osmotic resistance by the alkaline addition. Medic. Biol. 10: 135-138 (in Japanese).

49. Murakami, M. 1974. Hemolysis observed in continuous long distance running exercise in horses. Exp. Rep. Equine Hlth. Lab. 11: 120-127.

50. Murphy, J.R. 1967. The influence of $\mathrm{pH}$ and temperature on some physical properties of normal erythrocytes and erythrocytes from patients with hereditary spherocytosis. J. Lab. Clin. Med. 69: 758-775.

51. Oyewale, J.O. 1991. Osmotic fragility of erythrocytes of West African dwarf sheep and goats: Effects of temperature and pH. Brit. Vet. J. 147: 163-170.

52. Oyewale, J.O. 1992. Effects of temperature and $\mathrm{pH}$ on osmotic fragility of erythrocytes of the domestic fowl (Gallus domestics) and guinea-fowl (Numida meleagris). Res. Vet. Sci. 52: 1-4.

53. Pan, L.G., Forster, H.V., Bisgard, G.E., Kaminski, R.P., Dorsey, S.M., and Busch, M.A. 1983. Hyperventilation in ponies at the onset of and during steady-state exercise. J. Appl. Physiol. 54: 1394-1402.

54. Peinado, V.I., Alfaro, V., Palomeque, J., Palacios, L., and Viscor, G. 1993. Erythrocyte osmotic resistance during acute hypothermia in awake unrestrained rats. Pflugers Arch 424: 555-557.

55. Persson, S.G.B., Ekman, L., Lydin, G., and Tufvesson, G. 1973. Circulatory effects of splenectomy in the horse. II. Effect on plasma volume and total and circulating red-cell volume. Zbl. Vet. Med. A. 20: 456-468. 
56. Poso, A.R., Essen G.B., and Persson, S.G. 1993. Metabolic response to standardised exercise test in standardbred trotters with red cell hypervolaemia. Equine Vet. J. 25: 527-531.

57. Power, S.K. and Hamilton, K. 1999. Antioxidants and exercise. Clin. Sports Med. 18: 525-536.

58. Robin, H. and Harley, J.D. 1967. Regulation of methemoglobinemia in horse and human erythrocytes. Aust. J. Exp. Biol. Med. Sci. 44: 519526.

59. Rogausch, H. 1984. The flow behavior of lysolecithin-induced echinocytes. Biorbeology 21: 757-765.

60. Rose, R.J., Allen, J.R., Hodgson, D.R., Stewart, J.H., and Chan, W. 1983. Responses to submaximal treadmill exercise and training in the horse: changes in haematology, arterial blood gas and acid base measurements, plasma biochemical values and heart rate. Veterinary Record. 113: 612618.

61. Sagawa, S. and Shiraki, K. 1978. Role of lipids in stabilization red cell in rat. J. Natr. Vitaminol. 24: 57-65 (in Japanese).

62. Sakurai, N., Yamaoka, S., and Murakami, M. 1967. Relationship between exercise and changes in blood characteristics in horses. Exp. Rep. Equine Hlth. Lab. 4: 15-19 (in Japanese).

63. Shiraki, K. 1968. The effect of splenectomy on sports anemia. J. Physiol. Soc. Jpn. 30: 1-13 (in Japanese).

64. Singer, K. 1940. The lysolecithin fragility test. Am. J. Med. Sci. 199: 466-477.

65. Smith, J.A. 1995. Exercise, training and red blood cell turnover. Sports Med. 19: 9-31.

66. Smith, J.A., Kolbuch, B.M., Gillam, I., Telford, R.D., and Weidemann, M.J. 1995. Changes in the susceptibility of red cells to oxidative and osmotic stress following submaximal exercise. Eur. J. Appl. Physiol. Occup. Physiol. 70: 427-436.

67. Smith, J.A., Telford, R.D., Kolbuch, B.M., and Weidemann, M.J. 1997. Lactate $/ \mathrm{H}^{+}$uptake by red blood cells during exercise alters their physical properties. Eur. J. Appl. Physiol. Occup. Physiol. 75:
$54-61$.

68. Smith, J.E., Erickson, H., and Debowes, R.M. 1989. Changes in circulating equine erythrocytes induced by brief, high-speed exercise. Equine Vet.J. 21: 444-446.

69. Snow, D.H. and Martin, V. 1990. Effects of exercise and adrenaline on equine erythrocyte ATP content. Res. Vet. Sci. 49: 77-81.

70. Speakel, P.F., Roberts, C.A., and Gibson, J.S. 1997. Effect of changes in respiratory blood parameters on equine red blood cell K-Cl cotransporter. AJP Cell Physiol. 273: C1811-C1818.

71. Steiger, R. and Feige, K. 1995. Case report: Polycythemia in a horse. Schweiz. Arch. Tierheilkd. 137: 306-311.

72. Stocker, R., Yamamoto, Y., McDonagh, A.F., Glazer, A.N., and Ames, B.N. 1987. Bilirubin is an antioxidant of possible physiological importance. Science 235: 1043-1046.

73. Streuli, R.A., Kanofsky, J.R., Gunn, R.B., and Yachnin, S. 1981. Diminished osmotic fragility of human erythrocytes following the membrane insertion of oxygenated sterol compounds. Blood 58: 317-325.

74. Tanaka, N. and Hori, K. 1989. Study of sport anemia and its tendency. Clin. Sport Med. 6: 473482 (in Japanese).

75. Tesoriere, L., D’Arpa, D., Conti, S., Giaccone, V., Pintaudi, A.M., and Livrea, M.A. 1999. Melatonin protects human red blood cells from oxidative hemolysis: new insights into the radical-scavenging activity. J. Pineal Res. 27: 95-105.

76. Watanabe, S., Hanzawa, K., Hara, H., Ishikawa, Y., and Miura, N. 2000. Differentiation and maturation of equine erythroid cells from peripheral blood in a two phase liquid culture system. Anim. Sci. J. 71: 274-279.

77. Weiss, D.J., Geor, R.J., and Smith, C.M. 1994. Effects of echinocytosis on hemorrheologic values and exercise performance in horses. Am. J. Vet. Res. 55: 204-210.

78. Yoshimura, H. 1970. Anemia during physical training (sports anemia). Nutr. Rev. 28: 251-253. 